\title{
Exploration of a construction mode of teaching resources based on "education cloud"
}

\author{
Yao Pirong ${ }^{1}$; Zhang Yonghua ${ }^{2}$ \\ ${ }^{1}$ Yibin University's School of Computer \& Information Engineering \\ ${ }^{2}$ Yibin University's School of Experiment and Teaching Resources Management Center
}

\begin{abstract}
Information technology in the education process, many scholars in the study found that the construction of digital teaching resources in terms of quantity and efficiency in the use of hardware facilities are far behind the building; their main reason for this phenomenon is worth everyone to explore. Access to a large number of the many experts and recent research on the part of the school, It is the main reason in the process of the construction and use of teaching resources, that is too much reliance on the professionals did not fully mobilize the enthusiasm of the other ordinary subject teachers. Teaching resources to solve a number of constructions and use efficiency when it do to build shared, Wisdom campus based on "education cloud" will build a new teaching service platform for building and sharing of teaching resources.
\end{abstract}

Keywords: Education cloud; digital teaching resources; the era of cloud computing; construction mode

\section{The impact of cloud computing technology in education}

Cloud computing technology in the field of education migrate applications called "educational cloud", it is the future of in- formation technology in education infrastructure, including educational information with all necessary hardware computing resources, these resources have been virtualized, they will to educational institutions, educational practitioners and students to provide a good platform for the education sector's role is to provide cloud services.

"Education cloud" is essentially not a single site, but rather an educational information service platform, through the "one-stop" applications and "cloud" concept, trying to break the boundaries of education, information technology, allowing for all schools, teachers and students have one available, equality platform. "Cloud education 'in a way, through a unified, diverse platform for the education sector, schools, teachers, students, parents and other education-related parties, such as educational software developer, can enter the platform play different roles in this platform into teaching, management, learning, entertainment, communication and other types of application tools, so that "the true realization of educational informatization" ${ }^{[1]}$.

In promoting the modernization of education and information process, computer and network technology as the core of IT has played a very important role; However, in a single network server design mode, along with the process of education information doubling the amount of information generated many contradic- 
tions; example: teaching inefficient use of resources, access to the high cost of secondary development difficulties, the construction process specialization, etc.; cloud-core "educational cloud" development and implementation will be possible to solve in the construction of teaching resources faced problems help.

However, the "cloud era" still in its infancy, has not really come, so we first from the current Internet-based system and server plus terminal to truly realize the "cloud" before the transition period called "the cloud front of the times." At this special time of the past and we need to reflect and summarize education information network server era problems in the process, based on this study now the "cloud era front end" and the upcoming "cloud era" of teaching resources construction and development model ${ }^{[2]}$.

\section{Teaching resources are now facing problems in the construction and use efficiency}

At present, the levels of audio-visual education museum, Educational Technology Center as well as many school construction quality courses network teaching resources such as digital libraries and network teaching resources, they have greatly facilitate and promote the development of information technology in education; However, there are many local educational infrastructure needs to be improved, because sharing of digital educational resources has not yet formed an effective mechanism to promote information technology in education is still an urgent and arduous task ${ }^{[3]}$.

\subsection{Teaching Resources Construction of the platform is too specialized}

Currently in China, hindering the popularity of information technology in education is too important factor is the specialization that information construction of educational resources, such as network quality courses, teaching resources such as databases, their construction and maintenance only by the relevant professional teacher or full-time technical staff to complete, for most ordinary subject teachers and students can only download resources; thus forming a minority professionals to build, it is difficult to meet the needs of the majority of teachers and students of the situation. How to solve the difficulties faced by information technology in education is the education industry need to consider. Meanwhile, the resource update also requires relatively specialized technology, however, the person in charge of quality courses website is not necessarily able to complete the updating and maintenance of the network and technical personnel of various disciplines relevant expertise are proficient impossible.

Present in many colleges and universities, many teachers are not accustomed to using official or unit to build resource platform, but in the personal home computer use Serv-U to create their own personal teaching resource library, the reason lies in the use Serv-U construction of teaching resources in limited user rights and the use of space and other post; whether individual teachers in remote resource to read, write, delete, or student remote downloads and uploads, the operating system with the Windows Explorer exactly the same, only simple rather than professional IT.

\subsection{Low utilization of teaching re- sources}

Many times, when we talk about the modernization of education, information technology, always too many issues mentioned in the construction of hardware resources, such as the size of the campus network bandwidth, the bandwidth, the number of servers, etc.; But in recent years through the Yibin City, Sichuan Province an example of China's western 
region of modern educational technology environment survey found that: teaching inefficient use of resources in the western regions the main reason behind modern educational technology, already limited resources did not reach full utilization of information technology class coverage only a mere $2 \%-5 \%$, i.e.

More than $95 \%$ in the western region of classroom teaching or such traditional modes: a blackboard, a chalk plus a textbook, a preparation of this ${ }^{[3]}$.

Low utilization of teaching resources appear in addition to the western phenomenon, other regions also exist to varying degrees; their reasons, some scholars believe that: education industry investment diversification, repetition, uneven distribution of educational resources and education authorities can not control the resources, leading educational equipment utilization is not high, lack of effective use of teaching resources ${ }^{[4]}$. While another is technically scholars believe that the lack of uniform standards, by allowing network teaching resources in the curriculum and teaching management level knowledge exchange technical specifications (standards) is not widely recognized, the current construction of network teaching resources and the lack of uniform classification standards, developers are mostly based on their understanding and awareness on the classification and definition of teaching resources, lead to different network education system, different network teaching resources from universities into system, can not achieve effective communication and sharing ${ }^{[5]}$.

In addition, there may be many reasons, however, the field of education now has the hardware, there are resources, but inefficient use is an indisputable fact. From the above analysis we can see: teaching resources mismatch between supply and demand is the main reason. Why do I say? If the majority of teachers and teaching resources do not want to have the following characteristics, it will inevitably affect resource utilization:

(1) Get convenient: not too many complicated operations, such as: registration, install download tool software.

(2) Truly share: the so-called shared it should be completely free.

(3) Can be reprocessed: Resources on the basis of the original can easily modify and add their own teaching materials and teaching design.

Currently usual concept of digital learning resources are placed on the page, the site's server because access rights, technical standards, network hardware, and user level of technology and other aspects of the combined effects; together by a number of social enterprises or Group teaching resources need to pay to download and registration, payment and other aspects of the operation is complicated; and some resource providers to provide copyright protection too much emphasis on shared resources do not have the secondary processing, and so was not efficient use of these resources is also reasonable.

\section{The ideal model of teaching re- sources-- Building and Sharing}

Only by establishing a teaching resource Building and Sharing the new model, to solve the amount of resources and the efficient use of these two problems. In order to achieve this goal, we can assume that such a teaching resource construction mode: by professionals to build its hardware platform for the majority of users, especially general subject teachers to build digital teaching resources.

To achieve Building and Sharing must solve the following problem.

\subsection{Using popular, universal tech- nical standards}

In the process of building resources, in addition to the hardware platform, the 
material resources involved in the construction of information technology to popularize, he only needs to be able to operate with an ordinary computer and network infrastructure technology can; such broad general subject teachers have may be involved in the construction of digital teaching resources. Because, according to the Ministry of Education Teachers Division [2004] Document No. 9, "Teacher Education Technology Competency Standards (Trial)" in the first part of the "teaching staff educational technology standards," the second of knowledge and technology in the basic skills include:

(1) Access to information retrieval, processing and utilization methods.

(2) With the selection and development of methods for common instructional media.

(3) Grasp the general approach for teaching system design.

(4) Grasp the method for teaching resources management, teaching process management and project management.

(5) Master evaluation methods for teaching media, teaching resources, teaching process and teaching effect. ${ }^{[6]}$

As can be seen, the general teaching staff in educational technology ability of digital teaching resources on technology mainly in retrieval, processing, utilization, evaluation, which is now popularly known as the Normal School opened normal students "Computer Application Foundation" and "modern educational technology "involved in the information technology capabilities.

\subsection{Sharing and re-processing}

Resource sharing means that downloaded resources are free; while currently consists of many social enterprise or group needs to provide educational resources to pay to download and registration, payment and other aspects of complicated operation; addition, some authors empha- size copyright protection and the use of encryption, such providing shared resources can not be modified and processed.

If you provide shared resources have editable, can greatly improve the value and use of resources, especially courseware and multimedia material. Because each teacher's personality, strengths and teaching students to object, etc. are widespread disparities; shared courseware available online, he is very difficult to find a suitable classroom courseware, so it is necessary on the basis of a shared add your own courseware teaching materials and instructional design.

The use of such as Flash, Authorware and other software to make the generated files are only used while playing can not be modified unless accompanied upload source files; while using Office PowerPoint, WPS produced courseware can be very convenient for the majority of teachers modification. Therefore, the construction of teaching resources, unified file format digital resources will directly affect the efficiency of resource use.

\section{Learning Resources Prospects Based on "education cloud"}

Clouds will be on the development of educational teaching resources, and have a huge impact, in addition to savings for the purchase and maintenance of schools update the computer's costs, reduce maintenance and upgrade operating systems and application software costs, can be solved within the maximum resource sharing, lack of resources, the use rate and other issues; while providing secure data storage center, to solve the problem of insufficient storage resources ${ }^{[7]}$.

Based on the "educational cloud" "smart campus" solutions through continuous development in recent years, nearly mature; teaching which public service platform, will provide a specific teacher 
in the "cloud" for the establishment of a relatively independent and actual interoperability "space"; teachers simply by thin (Thin Client) using the authorized user name and password to connect the "cloud" service platform network teaching and research systems, network preparation system, teacher learning center system, teacher evaluation systems, resource management and application system, home school intercommunication systems, video recording and broadcasting ondemand system, remote network conference system, treasure trove of resources and other applications, to achieve onestop teaching of information technology.

Students also simply through a thin client access services in the same way on the platform of public service platform for students to learn through self-learning systems, interactive communication systems, networks, interactive classroom systems, network learning plan system, network information of student learning , to achieve distance learning and remote learn

\section{Acknowledgment}

The paper is one of the sub-topics derived from the focus of the research project of Sichuan Education Department, the name: the effectiveness of research-based thick foundation, large-caliber innovative university education mode; Item number 11 SA107.

\section{References}

[1] Baidu Library Education Area Educat ion / Science. [EB/OL].[2012-07-16]. http://wenku.baidu.com/view/00a33c d449649b6648d7472e.html.

[2] Yao Pirong, Explore the Construction and Development of Teaching Resources in the" Cloud Computing Era "[J], Modern Educational Technology, vol. 22. no.12, pp.112-114, 2012.

[3] Ceng chao. Education cloud: how to promote the development of information technology in education[EB/OL].[2012/7/31].http://storag e.it 168.com/a2012/0731/1378/000001 378868.shtml.

[4] Yao Pirong 、 Meng Lin. Research on the western part of the region's environment of modern educational technology [J], Journal of Teaching and Management, no.03, pp.77-78, 2008.

[5] Lin Liangliang. Online teaching resource sharing research $[\mathrm{J}]$, Modern Educational Technology, vol. 20. no.13, pp.85-87, 2010.

[6] Ministry of Education Teachers Division [2004] Document No. 9. Teachers Educational Technology Competency Standards (trial) [S]. Beijing: Ministry of Education, 2004.

[7] Wang Yufen;GuoXiaojuan. Analytic impact of cloud computing for Higher Education Resources [J], Experimental Technology and Management, no.05, pp.111-113, 2010.

[8] Era Think-tank Network Technology Co., Ltd. Cloud-based service platform for smart Campus Solutions [EB / OL]. [2012-8-1]. http://wenku.it168.com/d_000084719 .shtml. 